\begin{tabular}{|c|cc|}
\hline \multicolumn{3}{|c|}{ PORT-SAID ENGINEERING RESEARCH JOURNAL } \\
\hline
\end{tabular}

\title{
Detection of Road Surface Damage by Using Terrestrial Laser Scanner
}

\author{
Eslam Samir ${ }^{1}$, Ahmed El-Hattab ${ }^{2}$, Mohamed Ismail $^{3}$ and Ahmed El-Sharkway ${ }^{4}$
}

\section{Abstract}

Detection of road surface damages such as cracks, defects is very important and helps to identify the necessary maintenance to prevent accidents, evaluate road maintenance budgets and predicting the remaining service life of road.

In this research an automated method has been developed using MATLAB software to detect road surface damages depending on digital image camera. The classified and characterized cracks types are vertical, alligator or block, miscellaneous and transverse crack. The length and width of each type of crack can be determined, but the areas of damages are measured for alligator cracks. The 3D laser scanner as a modern survey equipment is utilized in this paper to assess and estimate the quantities required for maintaining some types of roads surface defects. The developed software and using 3D laser scanner show good efficiency to detect and classify the roads surface damages.

Keywords: Crack Detection, Image Processing, Road Defects.

\section{Introduction}

The road infrastructure is one of the most important elements that countries are concerned with, as they serve as the main element through which a continuous series of commercial, social and cultural activities that promote the national economy. Road construction projects are therefore the first choice in sustainable development programs and projects for countries wishing to achieve higher rates of development and growth.

\footnotetext{
${ }^{1}$ Civil Engineering Department, Faculty of Engineering, Portsaid University, portsaid, Egypt, E-mail: eslamsamir180@yahoo.com

${ }^{2}$ Civil Engineering Department, Faculty of Engineering, Portsaid University, portsaid, Egypt, E-mail: dr.ahmed.elhattab@gmail.com

${ }^{3}$ Civil Engineering Department, Faculty of Engineering, Portsaid University, portsaid, Egypt, E-mail: mohamedismail36@yahoo.com

${ }^{4}$ Civil Engineering Department, Faculty of Engineering, Portsaid University, portsaid, Egypt, E-mail:

A.elsharkawy@eng.psu.edu.eg
}

Roads are usually distorted and have defects due a combination of factors, rather than just one root cause.

The most important reasons are decrease in pavement load supporting characteristics, increase in loading, inadequate structural design, and inadequate structural design.

Evaluating the condition of transportation infrastructure is an expensive, time-consuming process, and labor intensive. Numerous streets assessment strategies use estimations taken in site alongside visual examinations and understandings. The estimation of deterioration and damage is frequently limited and qualitative to point observations.

In consideration of the problems stated above, a methodology to detect cracks in the surface of paved road is proposed using digital images and 3D data captured by scanner. 


\section{Types of Road Pavement Distresses}

There are many types for road pavement distresses [1], this research deals with the following types of distresses as shown in Figure 1: -

a. Cracking: is the most common distress class that appears in pavement surfaces and its causes are due to the fatigue of the asphaltic pavement layers (top pavement layers). They seem separated or as a progression of interconnected splits in the beginning periods of development, appearing also connected and with a higher density pattern in later stages.

Cracks can be defined as:

- Longitudinal Cracks

- $\quad$ Transverse Cracks

- Alligator Cracks

- miscellaneous cracks

b. Rutting: is a drop in the road surface (in the form of channels) in the tire path area. Rutting is related to loads, pavement thicknesses and materials and occurs as a result of the tuck and the occasional elastic movement of a layer or of all paving layers.

c. Potholes: Aging of asphalt materials by time result Potholes, so it happens in pavement surface with diameter less than $1 \mathrm{~m}$ due to heavy traffic, weakness of asphaltic design, existences of block or alligator cracks.

d. Patching (Repairs): removal of part of the surface asphalt layer and put a new asphalt mixture to fix the paving surface.

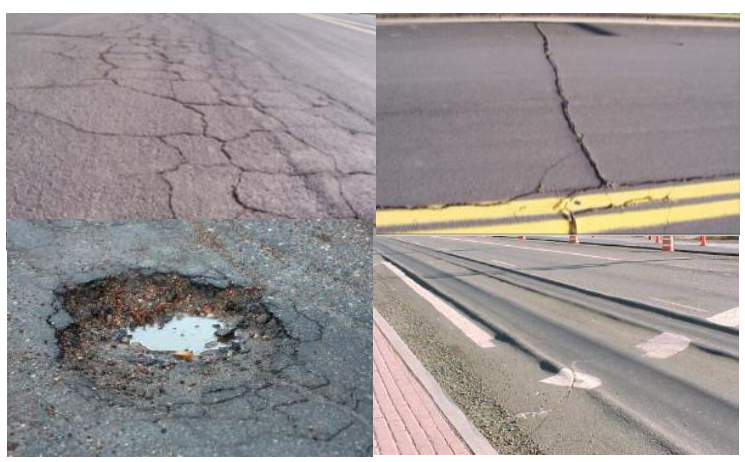

Figure 1: samples of road distresses

\section{Methodology of crack detections using digital images}

In the proposed methodology the following properties of crack is considered as recommended in Pavement Investigation / Test Method Handbook, 2007; Airport Pavement Repair Procedure and Design Example, 2015[2] :

- The width of crack is $1 \mathrm{~mm}$ or more.

- The length of crack is $20 \mathrm{~cm}$ or more where the cracks are not considered as crack if their length are less than $20 \mathrm{~cm}$ and exist independently.

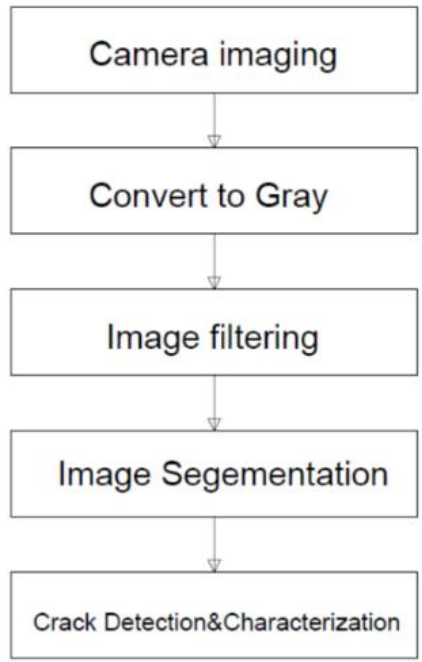

Figure 2: Working Steps Diagram to detect images cracks

Figure 2 shows the steps of crack detections methodology using digital images [3] \& [4]. MATLAB has been used to apply the proposed methodology to detect and classify the road surface cracks. The steps of the proposed methodology can be summarized as:

\subsection{Gray Image}

The digital image of the surface road which is stored as 3 data arrays; red, green, and blue (RGB) intensities $($ True color $(24-$ bit $))=16,777,216$ color variations $)$ to gray images $(8$-bit color $)=256$ colors $)$ [5].

$$
Y=0.229 R+0.587 G+0.114 B
$$


Where $\mathrm{R}$ is red intensity, $\mathrm{G}$ is green intensity, $\mathrm{B}$ is blue intensity and $\mathrm{Y}$ is the final merging intensity.

For many applications of image processing, edges or other features cannot be identify due to color information so gray scale considers fast and easy method to simplify image.

\subsection{Image Filtering}

Filtering operation is necessary to reduce noises and to blur the false/stray contour fragments in order to enhance the overall visual quality of the degraded image. In order to clean an image and enhance its feature as shown in Figure 3 [6].
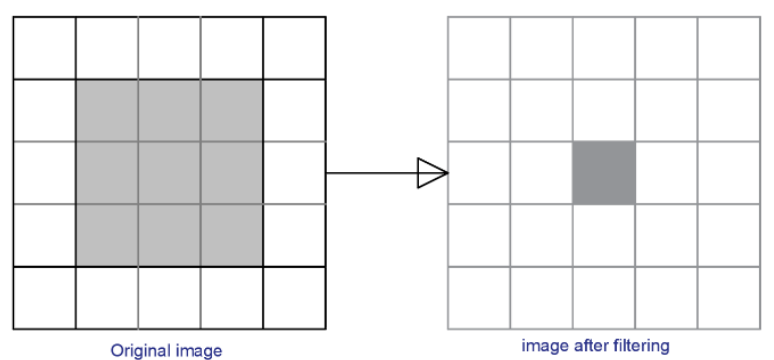

\begin{tabular}{|c|c|c|}
\multicolumn{3}{c|}{ Original image } \\
\hline A & B & C \\
\hline D & E & F \\
\hline I & G & H \\
\hline
\end{tabular}

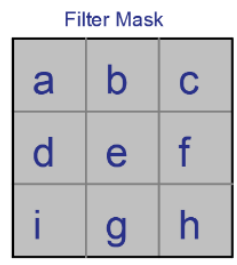

Figure 3: image before and after filtering

$$
\begin{aligned}
& \boldsymbol{E} \text { new }=\boldsymbol{A} * \boldsymbol{a}+\boldsymbol{B} * \boldsymbol{b}+\boldsymbol{C} * \boldsymbol{c}+\boldsymbol{D} * \boldsymbol{d}+ \\
& \boldsymbol{E} * \boldsymbol{e}+\boldsymbol{F} * \boldsymbol{f}+\boldsymbol{I} * \boldsymbol{I}+\boldsymbol{G} * \boldsymbol{g}+\boldsymbol{H} * \boldsymbol{h}
\end{aligned}
$$

Where capital letters are original intensity of image, small letters are the filter used.

Every pixel in matrix take average of the surrounding nine pixels, this called $3 * 3$ filter as shown in equation 2

\subsection{Image Segmentation}

Segmentation is to divide an image into objects or regions with respect to a particular application which make identification or detection easier as show Figure 4.

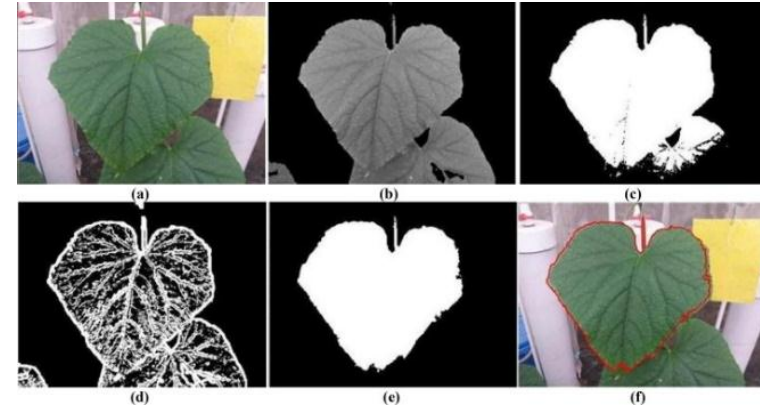

Figure 4: image segmentation of tree leaf

\subsection{Image Thresholding}

It is useful in differentiate foreground from the background [7] \& [8]. By selecting an adequate threshold value $\mathrm{T}$, the gray level image can be converted to binary image as shown Figure 5.

$$
\mathrm{G} 1=\{\mathrm{f}(\mathrm{m}, \mathrm{n}): \mathrm{f}(\mathrm{m}, \mathrm{n})>\mathrm{T}\} \text { (object pixels) }
$$

Pixels which has threshold greater than $\mathrm{T}$ will be white

$$
\mathrm{G} 2=\{\mathrm{f}(\mathrm{m}, \mathrm{n}): \mathrm{f}(\mathrm{m}, \mathrm{n}) \leq \mathrm{T}\} \text { (background pixels) }
$$

Pixels which has threshold smaller than $\mathrm{T}$ will be black

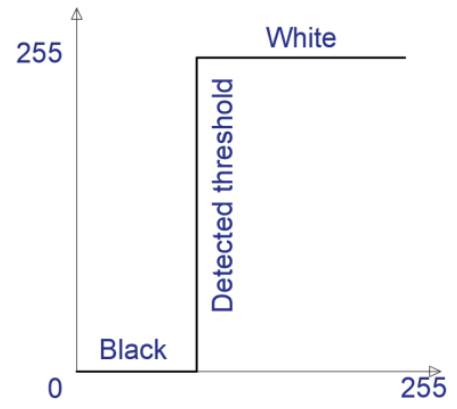

Figure 5 : Threshold Value

\subsection{Crack Detection and Characterization}

This method considered as semi-automated method, where some of the available images are considered as a sample to extract some information to be a reference for rest of images. The most important information is the threshold of the image which separates the crack from background area. Technique of cark detection is taken threshold of the nearest image's histograms and uses its threshold.

The proposed methodology can characterize the crack into vertical (Region I), alligator or block (Region II), 
miscellaneous (Region III) and transverse crack (Region IV). The length and width of each crack can be determined while the area for alligator cracks is estimated. To determine the dimensions of the road surface distresses, the pixel size of the image which depends on the position of camera has to be known. Figure 6 shows the four categories of crack classification.

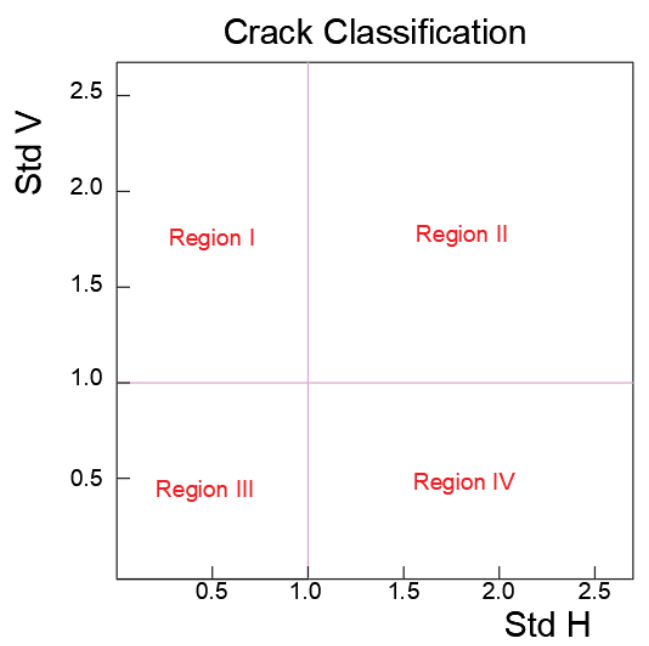

Figure 6: Crack Classification

\section{Methodology of defects detection using point clouds}

In the proposed methodology to detect the road surface defects, the following property of defects is considered:

Point Cloud is considered has defect if their elevation is higher or lower than datum level with $5 \mathrm{~mm}$, higher or lower than it gives illogical results .

Figure 7 shows the steps which have been used to detect defects from point cloud [9].

\subsection{Data Collection}

The data has to be captured by laser scanner and filtered with the manufacture software. The point cloud is exported as text as $3 \mathrm{D}$ coordinates and color after removing the noises in the next step

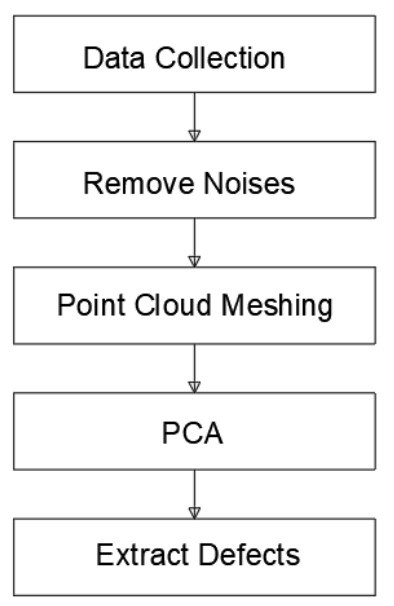

Figure 7: Working Steps Diagram to detect images cracks

\subsection{Remove Noises}

The point cloud normally has some noises which should be removed before the defection process. The noises can affect the defection process and lead to incorrect results. Figure 8 shows an example of noises removal from point clouds of road surface.

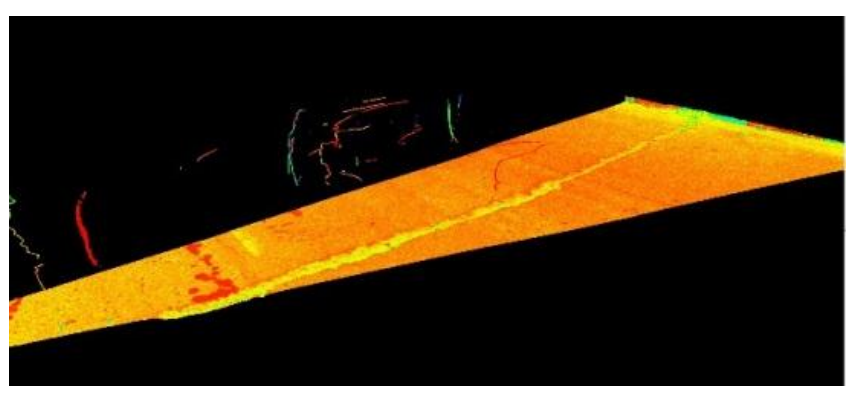

a. Point cloud with noise

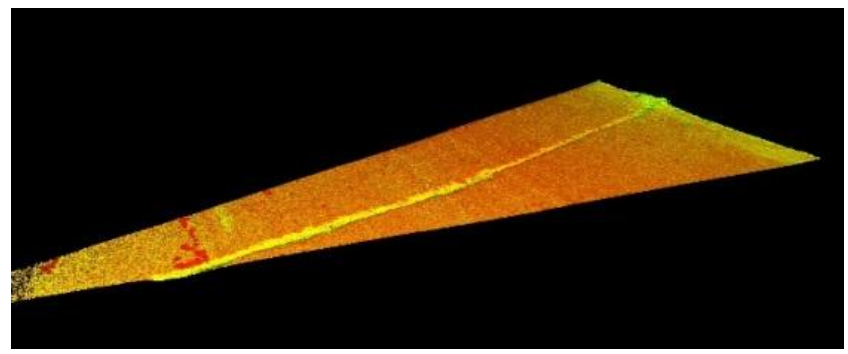

b. Point cloud after noise removal

Figure 8: Point cloud noises removal 


\subsection{Meshing}

Meshing is method used to combine point cloud as a shape, so it is become easy to deal with and considered as a surface. Therefore, locations and shapes of defects can be determined. Figure 9 shows an example of meshing point cloud.

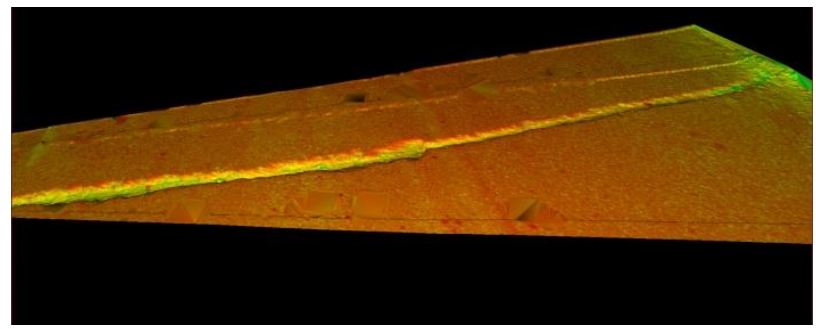

Figure 9: point cloud meshing

\subsection{Principal Component Analysis}

Principal components Analysis (PCA) is a procedure that uses an orthogonal transformation to convert set of observation of possibly correlated variables into asset of values of linearly uncorrelated variables as shown in Figure 10.

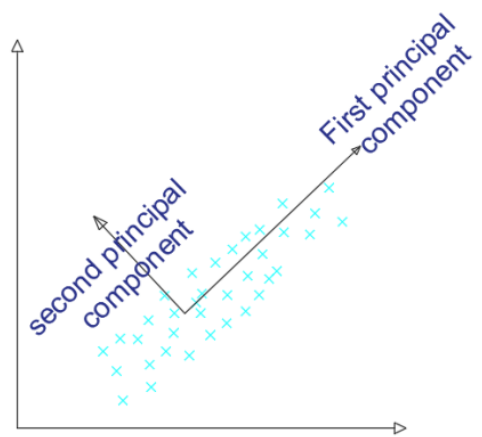

Figure 10: Principal Component Analysis

PCA is used to find the best surface in point cloud for detection defects.

\section{Experimental Evaluation of the proposed methodologies}

In order to evaluate the proposed methodologies several experiments have been performed, keep in mind the data captured from digital images and point clouds.

\subsection{Evaluation of crack detections}

\section{using digital images methodology}

To evaluate the proposed methodology for crack detection digital images for different types of cracks have been used.

For example, In Figure11 a threshold $=5$ is used, the resulting crack was as shown Figure 12 and the characterized crack was Horizontal as shown in Figure 13 [10].

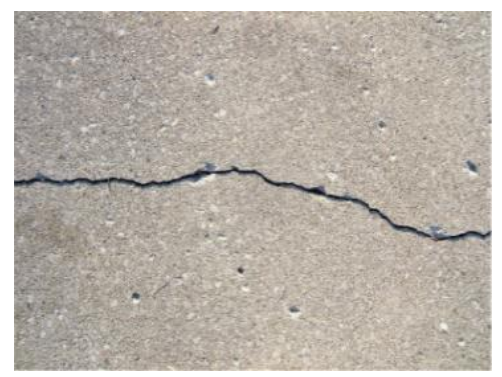

Figure 11: Actual image of crack

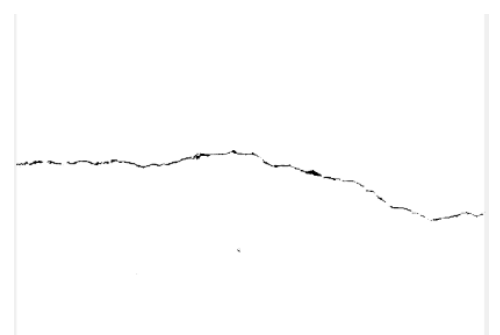

Figure 12: Crack after Detection

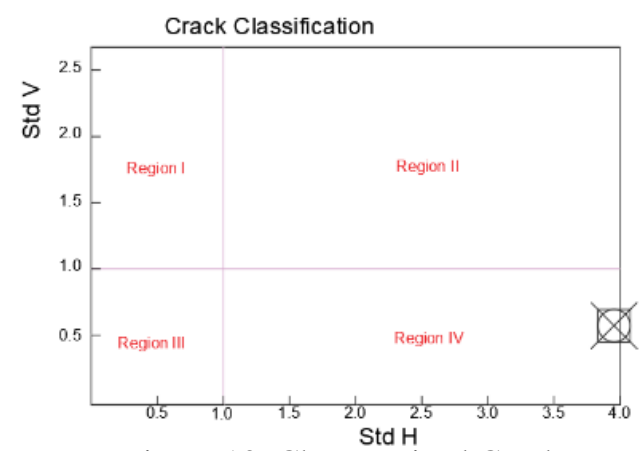

Figure 13: Characterized Crack

Also, more results of cracked and noncracked images are shown in Table 1. 
The table has five major columns: the detected cracks which shows number of pixels in width and height, horizontal and vertical standard deviation (pixel) which is a measure of the amount of variation or dispersion of a set of values and the concept used for classification, detected threshold which based on histogram of image, and the classification of these images.

Table 1: Results of image processing

\begin{tabular}{|c|c|c|c|c|c|}
\hline $\begin{array}{c}\text { Image } \\
\text { No. }\end{array}$ & Detected pixels & Std H & Std V & Classify & $\begin{array}{c}\text { Visual } \\
\text { classify }\end{array}$ \\
\hline 1 & $1350(600 * 900)$ & 0.71 & 4.46 & vertical & vertical \\
\hline 2 & $2795(1300 * 866)$ & 6.21 & 0.49 & Horizontal & Horizontal \\
\hline 3 & $1040(800 * 533)$ & 6.11 & 2.32 & Block & Block \\
\hline 4 & $(960 * 640)$ & 0 & 0 & no crack & no crack \\
\hline 5 & $2655(1300 * 839)$ & 5.75 & 0.69 & Horizontal & Horizontal \\
\hline 6 & $5184(1920 * 1080)$ & 9.94 & 6.79 & Block & Block \\
\hline 7 & $768(480 * 648)$ & 0.67 & 0.80 & miscellaneous & miscellaneous \\
\hline
\end{tabular}
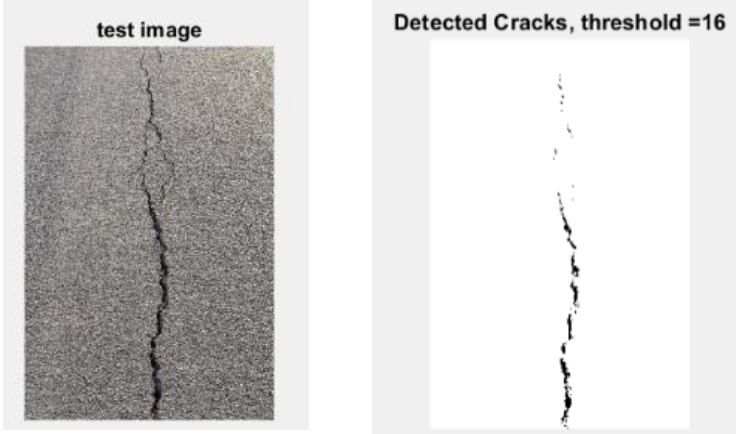

Figure 14: results of image No.1

Figure 14 shows Actual image the detected threshold= 16, the detected crack which has Hstd $=0.71$, Vstd $=4.46$ and the classification is Vertical.

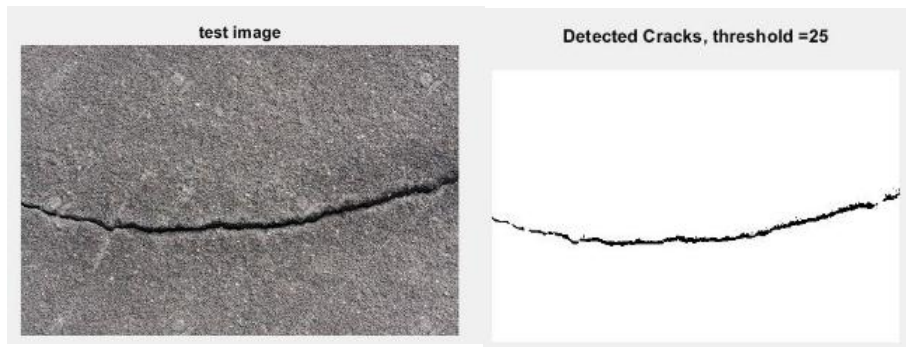

Figure 15 : results of image No.2
Figure 15 shows Actual image the detected threshold $=25$, the detected crack which has Hstd $=6.21$, Vstd $=0.49$ and the classification is Horizontal.
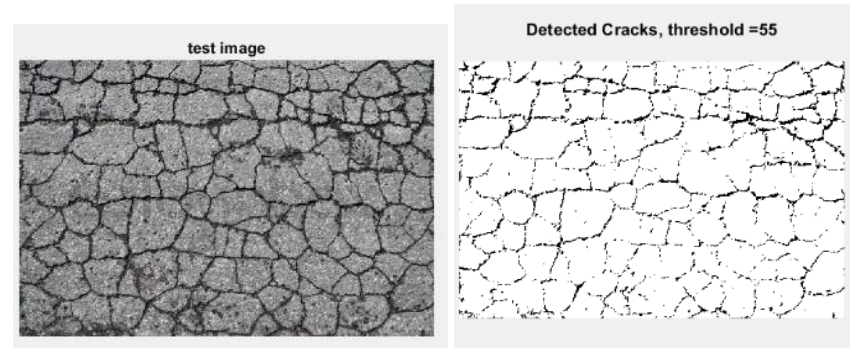

Figure 16 : results of image No.3

Figure 16 shows Actual image the detected threshold $=55$, the detected crack which has Hstd $=6.11$, Vstd $=2.32$ and the classification is Block.

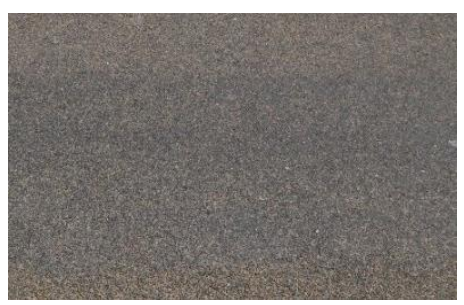

Detected Cracks, threshold $=33$

Figure 17: results of image No.4

In the proposed methodology if both horizontal and vertical standard deviation have values less than 0.3 the image is considered as non-cracked as image NO.4 in Figure 17

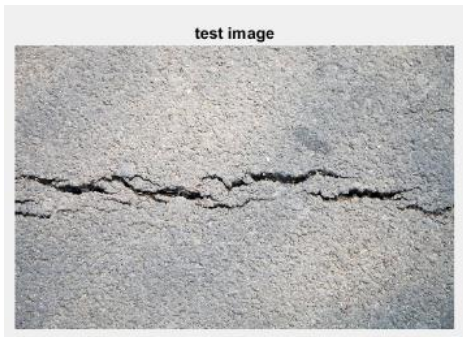

Detected Cracks, threshold $=7$

Figure 18: results of image No.5

Figure 18 shows Actual image the detected threshold= 7 , the detected crack which has Hstd $=5.75$, Vstd $=$ 0.69 and the classification is Horizontal. 

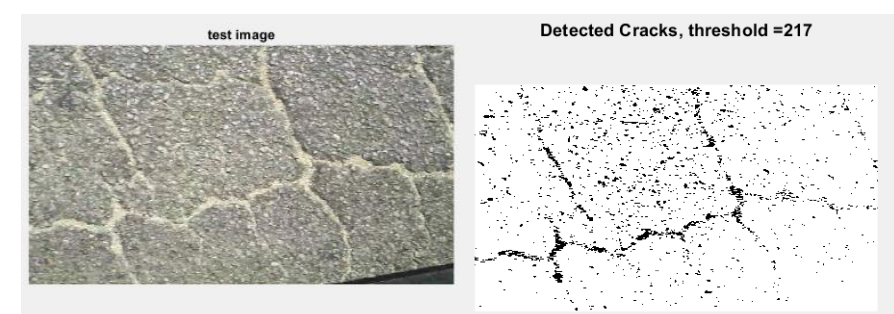

Figure 19: results of image No.6

Figure 19 shows Actual image the detected threshold $=217$, the detected crack which has Hstd $=$ 9.94, Vstd $=6.79$ and the classification is Block.
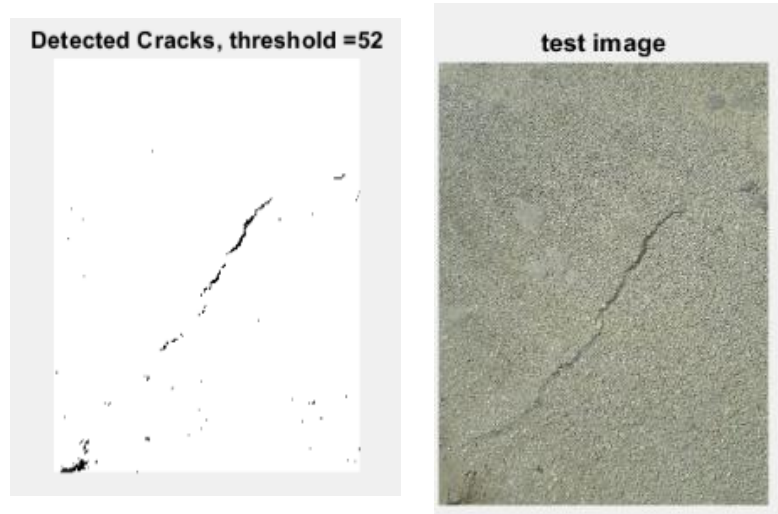

Figure 20 : results of image No.7

Figure 20 shows Actual image the detected threshold= 52 , the detected crack which has Hstd $=0.67, \mathrm{Vstd}=$ 0.8 and the classification is miscellaneous.

\subsection{Evaluation of defects detections}

\section{using point cloud methodology}

To evaluate the proposed methodology of defects detection using point cloud, 3D scans have been captured for 5 different places in Port Said city as shown in Figure 21. The point cloud has been captured using Leica P40- 3D Laser Scanner shown in

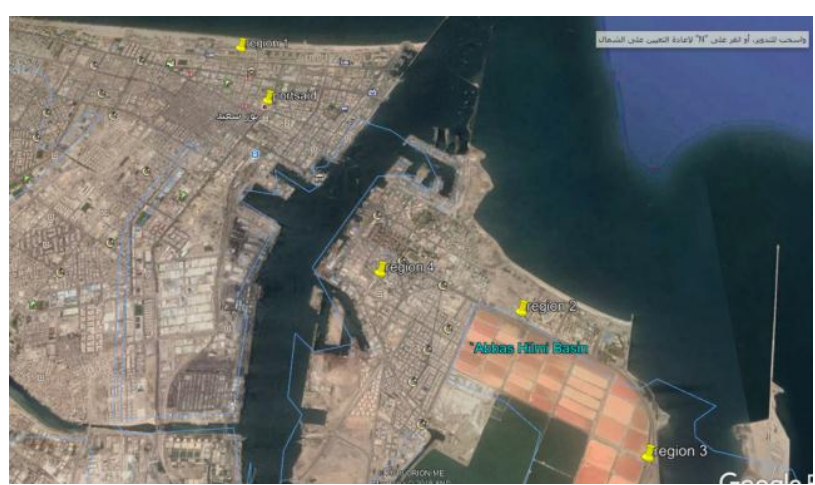

Figure 21: Working areas in Port Said

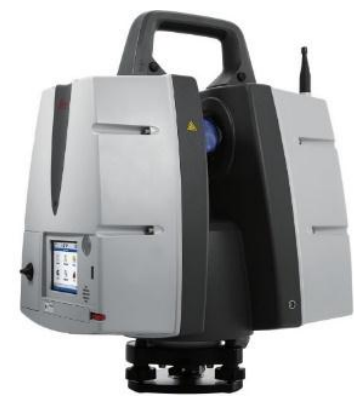

Figure 22: P40- 3D Laser Scanner

The first detected zone was at tar Tar-Elbhar Street. Figure 23 show the road defect as presented in Leica Cyclone software while Figure 24 shows the detected defects using the proposed methodology. The volume needed to repair this defect is also calculated.
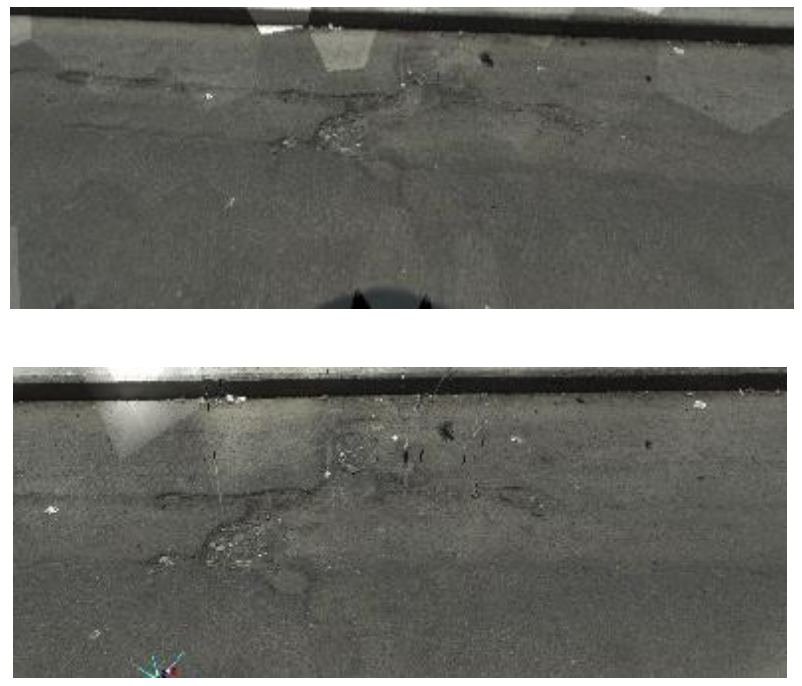

Figure 23: Region 1 from Cyclone software 


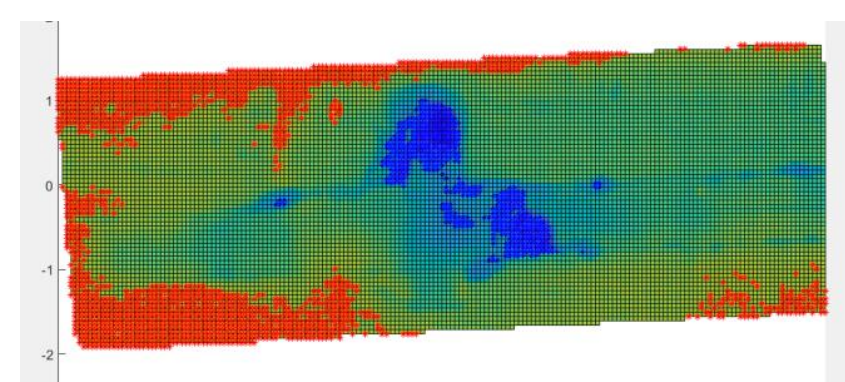

Figure 24: detection of defect

The second detected zone was at Port Fouad city. Figure 25 show the road defect as presented in Leica Cyclone software while Figure 26 shows the detected defects using the proposed methodology. The volume needed to repair this defect is also calculated.

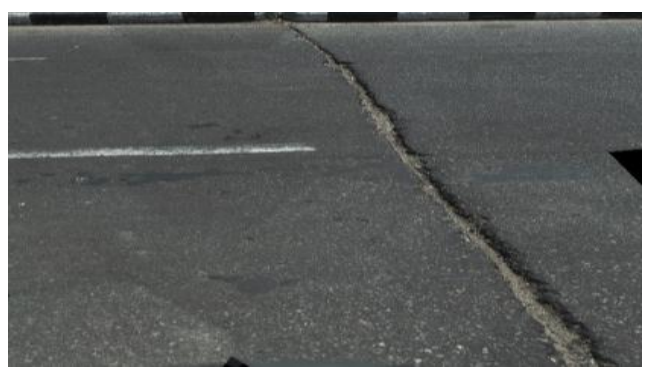

Figure 25: Region 2 from Cyclone software

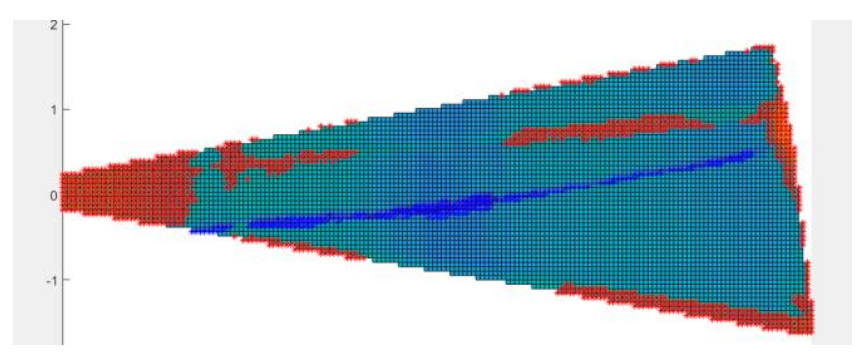

Figure 26: detection of defect

\section{Conclusion}

This paper studies the detection of roads damages to help identify immediate maintenance, evaluate road maintenance budgets and predicting the remaining service life of road. Methodologies are proposed in this study to detect and classify the surface road defects using digital images and point clouds. Based on the proposed methodologies, a software has been developed by MATLAB and has been evaluated using different digital images and points clouds. The results showed that the developed software successfully DOI: 10.21608/pserj.2020.19352.1017 detected and classified the road surface defects. Experimental results show that developed software can be used in real life.

\section{References}

[1] Coenen, Tom BJ, and Amir Golroo. "A review on automated pavement distress detection methods." Cogent Engineering 4.1 (2017): 1374822.

[2] Pavement Investigation / Test Method Handbook, 2007; Airport Pavement Repair Procedure and Design Example, 2015

[3] Mohan, Bhavani, Kasthuri, Varun and Bhavya, "Detection and Quantification of Road Surface Damage using Digital Image Processing Techniques" International Journal of Engineering Research \& Technology (IJERT) (2017).

[4] Choi, J., L. Zhu, and H. Kurosu. "Detection of cracks in paved road surface using laser scan image data." Int. Arch. Photogrammetry, Remote Sens. Spatial Inf. Sci. 41 (2016): 559-562.

[5] Bao, Guanqun. Road distress analysis using 2D and 3D information. Diss. University of Toledo, 2010.

[6] Ouyang, Aiguo, Chagen Luo, and Chao Zhou. "Surface distresses detection of pavement based on digital image processing." International Conference on Computer and Computing Technologies in Agriculture. Springer, Berlin, Heidelberg, 2010.

[7] B. Hari Prasath, S. Karthikeyan, Mrs.G. Mary Valantina "Computerized Highway Defects Recognition and Classification System" International Journal of Pharmacy\& Technology, IJPT, March-2016, Vol. 8, Issue No.1, 11038-11048.

[8] Oliveira, Henrique José Monteiro. Crack detection and characterization in flexible road pavements using digital image processing. Diss. $\mathrm{PhD}$ thesis, Universidade de Lisboa-Instituto Superior Técnico, 2013. 
[9] Yamada, Taichi, Takeru Ito, and Akihisa Ohya. "Detection of road surface damage using mobile robot equipped with $2 \mathrm{~d}$ laser scanner." Proceedings of the 2013 IEEE/SICE International Symposium on System Integration. IEEE, 2013.

[10] Moon, H., and J. Kim. "Intelligent crack detecting algorithm on the concrete crack image using neural network." Proceedings of the 28th ISARC (2011): 1461-1467.

[11] Karaköse, Mehmet, et al. "A fast and adaptive road defect detection approach using computer vision with real time implementation." International Journal of Applied Mathematics, Electronics and Computers 4. Special Issue-1 (2016): 290-295. 